\title{
General Chemistry: Large Classes, Mixed Public, Three Languages (A Personal Experience)
}

\author{
Katharina M. Fromm*
}

\begin{abstract}
At most universities, teaching general chemistry to fresh(wo)men is a challenge as the audience is usually composed of students of different backgrounds and interests. On one hand, the lecture is meant to bring all students to a basic level of chemistry required for future studies, on the other hand, certain concepts are discussed in much more depth than what students know from school. While it is already a balancing act to teach the content to students with little chemistry knowledge without boring those who took intensive classes at school, the University of Fribourg adds a challenge by teaching officially bilingual classes.
\end{abstract}

Keywords: Diversity in students · Experiments in lectures · General chemistry teaching · Large classes . Plurilinguistic teaching

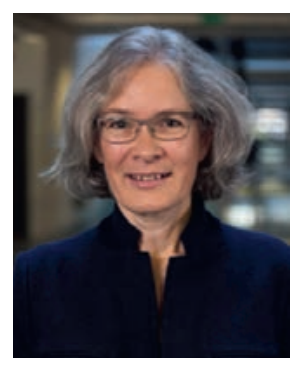

Katharina M. Fromm grew up in Germany, France and the USA, providing her with a plurilingual culture. After a habilitation in Inorganic Chemistry in Geneva and an SNSF professorship in Basel, she teaches the General Chemistry Classes (and others) at the University of Fribourg since 2006. She maintains a large research group with focus on nanomaterials (batteries, antimicrobial coatings) and the bioinorganic chemistry of silver, and became, after serving as Research Councilor for the SNSF during nine years, Vice-President for Research and Innovation of the University of Fribourg in January 2020. Teaching the large 6h/week classes of General Chemistry in at least two languages, including the experimental Christmas Show, is her favourite teaching activity in the autumn semester, while in spring, she teaches smaller classes, e.g. Chemistry of the Elements, Solid State Chemistry and, if time permits, Bioinorganic Chemistry.

\section{Introduction}

The Universities in Switzerland have two tasks, one is doing (basic) research, the other is about teaching the next generation of scientists. Both research and studying go holistically hand in hand in the ideal Humboldtian model of a university, and we should strive at this remaining so. Indeed, Wilhelm von Humboldt explained his educational model in a letter to the Prussian king, where he wrote: "There are undeniably certain kinds of knowledge that must be of a general nature and, more importantly, a certain cultivation of the mind and character that nobody can afford to be without. People obviously cannot be good craftworkers, merchants, soldiers or businessmen unless, regardless of their occupation, they are good, upstanding and-according to their condition - well-informed human beings and citizens. If this basis is laid through schooling, vocational skills are easily acquired later on, and a person is always free to move from one occupation to another, as so often happens in life."[1] In this sense, the propaedeutic teaching in mathematics, physics, biology and chemistry, as it is found in many European Universities in the first year teaching programs for students in classical branches of
Natural Sciences, plays an important role in the basic education. At this stage, students can still easily change their study branch depending on their gusto. These propaedeutic courses are usually intensive teaching units that allow students from different backgrounds to be brought to the same level of knowledge, as the basis for future vocational studies. Among these, the General Chemistry lecture, which is taught at the University of Fribourg at a rhythm of six hours per week, including exercises and live experiments, is found. In the following sections, the particular situation of teaching such classes at an officially bilingual university will be described in detail, with the aim to highlight on the diversity of students, their background and language skills as well as the particular challenges that may arise from such lectures.

\section{The General Chemistry Lectures at the University of Fribourg}

First, the general situation of the Department of Chemistry at the University must be laid out. With a total of eight professors, the Department of Chemistry at the University of Fribourg has a small number of permanent teaching staff, supported by a senior research position, colleagues from the Adolphe Merkle Institute (AMI) of our University and a couple of outside teaching assignments to cope with the overall curriculum. Embedded in a full Faculty of Science and Medicine - Fribourg is the only University to have the Sciences and Medicine united within the same Faculty (which is an advantage for close interdisciplinary research activities by the way) - service teaching to other Departments is another important task during the first two years of the Bachelor studies, but also, to a smaller extent, in the Master program.

There are two ways of coping with such service teaching. One option is to give multiple courses of General Chemistry, and to adapt the content to the minimum requirements needed in each study branch. This leads then to a multiplication of courses, called 'General Chemistry for ...', depending on the clients (e.g. for pharmacists, for teachers, for biologists, etc.). While other universities may have the luxury to split this service teaching over several teachers, the University of Fribourg follows the second way, teaching almost all fresh(wo)men together in one class. 
This has the big advantage that all students in the propaedeutic classes get the same high-level education, hence the one adapted also for chemists, allowing them to easily change in between the different study areas after one or two semesters, if desired. Fitting the Humboldtian model, this education allows to keep up the highest level of teaching and education to all.

Hence, when I started to teach the classes of General Chemistry, taking over from Alex von Zelewsky in 2006, I found myself in front of $c a .250$ students from different branches: chemistry, biochemistry, physics, biology, geosciences, mathematics, informatics and medicine - and even some students from history or philosophy. These students had obviously different, more or less strong motivations to learn about general chemistry.

When the University of Fribourg introduced new study branches, such as biomedicine and sports, the number of students having to follow the lectures in General Chemistry quickly increased to more than 350. As the big auditorium of the Chemistry Department, which is the largest of the Faculty of Sciences and Medicine, could at the time host $\mathrm{ca} .300 \mathrm{stu}-$ dents, one can imagine the situation with students sitting on the stairs. This is of course a no-go in an experimental course where safety has to be guaranteed, so a quick solution had to be found. Today, there is now a General Chemistry lecture for students in medicine, at four hours per week, given by colleagues, and there remains the 'big' lecture at six hours per week for all the other students, still easily filling the big lecture hall. This is now the situation from where I will take my discourse onward.

\subsection{Nationalities and Languages}

Over the past 14 years that I taught the 'General Chemistry' course, students originated, apart from Switzerland, from 30 different countries, ranging from Germany and France as next neighbors and hence largest groups, to countries like Algeria, Azerbaidjan, Burkina Faso, Congo, all across the world including Mexico or Singapore to Turkey (alphabetical order). While these foreign students remained minorities with 10-25 students per year, the majority of participants came from the home canton Fribourg (Table 1), followed by Berne, Wallis and Ticino.

Over the past ten years, the language distribution has shifted from a slight majority of German-speaking participants to a slight majority of French-speaking students (Table 2). Surprisingly, only few students call themselves bilingual upon arrival. The amount of Italian-speaking participants increased over the past years to close to $10 \%$, which might be due to the recent arrival of three new colleagues with Italian backgrounds, Profs. Lattuada, Zobi and Dr. Ruggi in our department.

Fribourg, as an officially bilingual university, aims at educating students in the Chemistry curriculum such that they can become trilingual at the end of their studies. This means that some lectures, like the 'General Chemistry' course, are held officially in two languages, German and French, other classes are monolingual in either French or German (on BSc level) or English (advanced courses at $\mathrm{BSc}$ and MSc level). With this approach, students will reach a minimum of scientific vocabulary in the three languages when obtaining a Master degree, giving them a distinct advantage on the job market.

\begin{tabular}{|c|c|c|c|c|c|c|}
\hline Canton & 2013 & 2014 & 2015 & 2016 & 2017 & 2018 \\
\hline $\begin{array}{l}\text { Appenzell } \\
\text { AR }\end{array}$ & & 1 & & & & 2 \\
\hline $\begin{array}{l}\text { Appenzell } \\
\text { IR }\end{array}$ & 2 & 4 & 2 & & 1 & \\
\hline Aargau & 19 & 19 & 23 & 19 & 10 & 21 \\
\hline Basel-Land & 8 & 3 & 7 & 1 & 4 & 1 \\
\hline Basel-City & & 1 & 2 & & 1 & \\
\hline Berne & 35 & 44 & 38 & 40 & 39 & 52 \\
\hline Fribourg & 92 & 97 & 106 & 118 & 102 & 88 \\
\hline Geneva & 4 & 3 & 2 & 7 & 3 & 5 \\
\hline Glarus & 3 & & & 1 & & \\
\hline Grisons & 5 & 14 & 9 & 6 & 8 & 7 \\
\hline Jura & 7 & 12 & 8 & 11 & 10 & 11 \\
\hline Lucern & 17 & 9 & 15 & 12 & 11 & 12 \\
\hline Neuchatel & 8 & 5 & 11 & 8 & 6 & 7 \\
\hline Nidwald & 3 & 3 & & 1 & 3 & 1 \\
\hline Obwald & 1 & & & 3 & 1 & \\
\hline Saint Gall & 18 & 22 & 15 & 13 & 7 & 6 \\
\hline Schaffhouse & 3 & 4 & 3 & 2 & 3 & 2 \\
\hline Schwyz & 5 & 6 & 9 & 6 & 2 & 1 \\
\hline Solothurn & 11 & 8 & 12 & 8 & 5 & 6 \\
\hline Ticino & 33 & 35 & 25 & 34 & 31 & 36 \\
\hline Thurgau & 6 & 12 & 7 & 10 & & 4 \\
\hline Uri & 1 & 1 & 1 & & 4 & 3 \\
\hline Wallis & 18 & 26 & 34 & 26 & 42 & 41 \\
\hline Vaud & 7 & 15 & 19 & 17 & 24 & 22 \\
\hline Zug & 3 & & 7 & 3 & 2 & 3 \\
\hline Zurich & 7 & 10 & 9 & 8 & 8 & 7 \\
\hline
\end{tabular}




\begin{tabular}{|l|r|r|r|r|r|r|}
\hline Year & $\mathbf{2 0 1 3}$ & $\mathbf{2 0 1 4}$ & $\mathbf{2 0 1 5}$ & $\mathbf{2 0 1 6}$ & $\mathbf{2 0 1 7}$ & $\mathbf{2 0 1 8}$ \\
\hline German & 169 & 157 & 191 & 158 & 135 & 141 \\
\hline English & 3 & 2 & 7 & 2 & & 5 \\
\hline $\begin{array}{l}\text { Other } \\
\text { Bilingual }\end{array}$ & 11 & 22 & 11 & 14 & 13 & 12 \\
\hline G/f & & 6 & 4 & 3 & 1 & 1 \\
\hline $\begin{array}{l}\text { Bilingual } \\
\text { F/g }\end{array}$ & 1 & 5 & 4 & 5 & 3 & 9 \\
\hline Spanish & 1 & & & & & \\
\hline French & 123 & 152 & 140 & 159 & 160 & 149 \\
\hline Italian & 25 & 21 & 21 & 26 & 30 & 30 \\
\hline Romansh & & 1 & & 1 & & 1 \\
\hline $\begin{array}{l}\text { Total } \\
\text { number }\end{array}$ & 333 & 366 & 379 & 368 & 342 & 348 \\
\hline
\end{tabular}

Upon my arrival in Fribourg on October $1^{\text {st }} 2006$, and the semester starting two weeks later, I had to put together the $6 \mathrm{~h} /$ week course in a very short time. This was possible with the help of my former Basel colleagues, but it also meant that many slides were in German. I also inherited the scripts from my predecessor Alex von Zelewsky, which existed in both languages, German and French. With this in hand, and my own additions, I put together the lecture which has today roughly 720 slides for the general chemistry, and an additional manuscript for the general organic chemistry, which is integral part of my lecture, of $c a$. 50 pages. The PowerPoint slides are typically complemented with explanations or details given on the blackboard for the general chemistry part, except for the general organic chemistry chapter, which represents approximately one quarter of the examinable content. This latter part is entirely handwritten on the Openboard screen, and students are asked to copy and take notes as we progress. This is in order to change lecture style, and for students to better learn the content of this part of the lecture as they need to be able to draw organic molecules on paper during the exam. Although I explain this to the students, some rather prefer to take pictures of what is written, which usually leads to corresponding results (see Section 2.5).

Around $80 \%$ of the slides are in German, the others in French and English. This however does not prevent me from teaching bilingual, German in the first hour and French in the second hour of the three weekly two-hour slots. Of course, without repeating the content of the previous hour, but rather going on with the content of the lecture. At this point, I should mention that all important points and concepts are repeated in both languages to make sure that the students understand, and I usually observe my audience very well in order to verify that they understood well. On top of that, I regularly ask the question in both German and French, if important messages are clear, and nodding heads encourage the professor then to move forward. Also, some students raise their hands to ask questions, which I allow of course, although this risks losing the attention of other students. I typically repeat the question of the student and reply in both, German and French. Many students come during the break or after the lecture to ask individual questions for which I usually take enough time until everyone is satisfied.

\subsection{Different Backgrounds}

Just as the students come from many different regions around the world and Switzerland, they also come with very different knowledge in chemistry. Acting as expert for the written chemistry graduation exams (Maturité) of several local high schools, I gain good insight into what first semester students already know if they took chemistry as one of their major areas. They have already a good background in simple atom theory, acid-base chemistry, electrochemistry and organic chemistry. But many students did not take a chemistry major and sometimes did not have chemistry classes at all during their final years at high school. Thus, the incoming knowledge levels are very different. It is my role to bring everyone up to date with basic chemistry (and more), so that the students have a good backpack of knowledge to study further in any of the desired fields. It is furthermore likely that the motivation to learn about general chemistry is probably not identical among students as they do not necessarily have their primary interest in this area. This is reflected by the different study lines shown in Table 3.

Along with varying knowledge levels in chemistry come very different levels of mathematics, and sometimes the simple rule of three (cross-multiplication) leaves a complete blank on some faces in my lecture hall. Thus, some questions asked by students during the lecture may lead to raised eyebrows. For example, when explaining the molar mass of e.g. $180 \mathrm{~g} \cdot \mathrm{mol}^{-1}$, a hand popped up and the question came: "Where does the negative charge on the 'mol' come from?". Also, in the kinetics chapter, simple integrations and derivatives in the context of zero, first and second order reactions seem regularly to pose problems. On top of that, the speed at which the content is taught is of course faster than at high school, and students need to adapt to this new rhythm.

All along the semester, the students are given exercises, which they can solve at home if they want to (there is no obligation), and the exercises are then solved during the lectures at given dates. At this moment, the students typically divide into those who stay for the exercises and want to see how they are solved, and those students who either think they already know it all, or they are not interested or think that the solutions will be anyhow given in a written form (which indeed is so, but only near the end of the semester). Exercise sessions are nevertheless important as they allow to detect weaknesses, to hear more questions being asked than during the lecture, and to repeat or re-explain some of the theory to those who are there. At this point, I wish to acknowledge and thank my co-workers and students who have helped me over the years with the exercises, especially on those dates, for example, when I was at SNSF.

\subsection{Experiments}

Chemistry is essentially an experimental science with the theory being developed such as to best describe the observations, and it goes without saying that such a lecture lives from experimental illustrations. Thus, chemical reactions that are exo- or endothermic, colourful acid-base titrations, illustrations of the galvanic series, impressive oxidation-reduction reactions or color- 


\begin{tabular}{|c|c|c|c|c|c|c|}
\hline $\begin{array}{l}\text { Main Study } \\
\text { Branch }\end{array}$ & 2013 & 2014 & 2015 & 2016 & 2017 & 2018 \\
\hline $\begin{array}{l}\text { Social Sci. \& } \\
\text { Humanities }\end{array}$ & & 1 & 1 & & & \\
\hline $\begin{array}{l}\text { Sciences \& } \\
\text { Med. (total) }\end{array}$ & 333 & 365 & 378 & 368 & 342 & 348 \\
\hline $\begin{array}{l}\text { Biochem- } \\
\text { istry }\end{array}$ & 5 & 18 & 11 & 7 & 14 & 15 \\
\hline Biology & 48 & 46 & 62 & 71 & 69 & 74 \\
\hline Chemistry & 15 & 17 & 20 & 20 & 18 & 13 \\
\hline Geography & & & & & 1 & \\
\hline Geosciences & 2 & 6 & 6 & 14 & 2 & \\
\hline Dental Med. & 21 & 16 & 16 & 20 & 4 & \\
\hline Human Med. & 99 & 112 & 106 & 105 & 90 & 103 \\
\hline Pharmacy & 13 & & & & & \\
\hline Physics & 2 & 4 & 4 & 3 & 2 & \\
\hline $\begin{array}{l}\text { Earth } \\
\text { Sciences }\end{array}$ & 2 & 6 & 16 & 11 & 2 & 9 \\
\hline $\begin{array}{l}\text { Environmen- } \\
\text { tal Sciences }\end{array}$ & & 3 & & & 2 & \\
\hline Biomed. Sci. & 104 & 103 & 108 & 91 & 109 & 104 \\
\hline $\begin{array}{l}\text { Maths/Nat. } \\
\text { Sci. }\end{array}$ & 12 & 10 & 22 & 15 & 22 & 17 \\
\hline \multirow[t]{2}{*}{ Sports } & 10 & 24 & 7 & 11 & 7 & 13 \\
\hline & 333 & 366 & 379 & 368 & 342 & 348 \\
\hline
\end{tabular}

changing equilibria as a function of temperature need to be shown in every general chemistry lecture. Such experiments, shown live in the lecture hall, help to transmit enthusiasm and amazement in front of the beauty of these reactions. They are also an appreciated tool to pair the theory with real effects. Of course, in a big lecture hall, one is tempted to use large enough quantities to enable even the student in the last row to see the experiment, but modern techniques using live video transmission allow to handle also quite exothermic reactions at a controllable scale, while projecting the ongoings on a large screen. Filming the reaction with a high quality camera allows also transmitting hard data, such as temperature changes indicated on a digital thermometer, which would otherwise be too small to be read even by students in the first row. My personal experience is that all students are typically attracted by these experiments, and in every evaluation of my lecture, this was highly appreciated. It goes without saying that the reactions are well chosen and tested in advance, and should not put anyone into danger. This is why protective gear and screens for the audience are needed, but it also requires a mobile hood, a preparation and storage room for these experiments, appropriate lighting in the lecture hall and a chemical-resistant bench on which these experiments can be carried out. Above all, an excellent scientific collaborator is needed, who knows all the tricks in order to make the experiments work and look good. Over the past 14 years, this used to be Michel Piccand, who, after his retirement, handed over to Dr. Aurélien Crochet.

\subsection{The Christmas Show}

Very much inspired by the UK tradition of the Royal Society of Chemistry Christmas lectures, by my own upbringing as a chemist at the University of Karlsruhe in Germany, by my own faible to do spectacular reactions, by books describing such reactions, by the tradition of my predecessor and by own previous experience, I always offered a Christmas Chemistry Show. This was already so when I was a Maître-Assistant in Geneva, and as Assistant Professor in Basel, and has happened since 2006 in Fribourg. My predecessor topped this with an additional Christmas movie in which the students were included. This put me in front of quite a challenge - but I accepted it. Since 2006, every single year, we filmed a movie on a specific theme, and for which I acted as the playwright. Some of these movies include titles inspired from movies, TV series, operas or famous theatres, such as 'Back to the Future', 'CSI Miami', 'Miss Marple', 'James Bond', 'Ghost Busters' and others. Titles and content were of course adapted to locations and filled with other stories, to become e.g. 'CSI Fribourg', our very first movie in 2006. A former $\mathrm{PhD}$ student, Fabienne Gschwind, whose hobby was (and still is) film making, has created for us, in analogy to the $20^{\text {th }}$ Century Fox, Metro Goldwyn Mayer or similar film making intros, a 'Fromm Group Production' intro, which is now used for every movie made by the Fromm group, and which always leads to first laughter by the students when the movie is shown either at the beginning or the end of the Christmas show (depending on whether it serves as intro or as follow-up of the show). Although the story is always fun, the students love the passages of the movie in which they can see themselves in the lab or during the lectures - and of course, we always integrate them.

The Christmas shows themselves were and are also inspired by famous books, movies, TV series and operas, for example 'The Magic Flute', 'Aladdin', 'Lord of the Rings', 'Asterix and Obelix', 'The Roaring Twenties', 'Blues Brothers', 'Men (and women) in Black' and so on. In 2010, the Harry Potter-derived show was so successful that we did charity shows following the Haiti earthquake and raised 10'000,- CHF, which was donated to the Red Cross for Haiti support. Every year, the Chemistry show not only attracts the first semester students, but on top of that, many permanent scientists of the Chemistry Department and the entire Faculty come to see the event. We have had also quite some 
media coverage already in the past. In any case, this is a yearly highlight, for which the members of the entire Fromm research group as well as other department members prepare, choosing their favourite reactions and putting them into the scenes, together with the choice of appropriate costumes. It goes without saying that the 'Blues Brothers and Sisters' show in 2018 had for instance to give credit also to Aretha Franklin. Thus, events during the year usually give a lot of input for this end of year shows, and the scripts for both, the movie and the show, always evolve over the year; and they are always rewarded by a big applause. Students seem to remember these shows very much, as some of my former students tell their friends, colleagues and family about it, and sometimes, such stories about "the crazy chemistry professor" are reported back to me in one way or another. Also, after the show, it is usually difficult to go 'incognito' shopping in a small city like Fribourg without having groups of young students pointing at me and laughing a very gentle laugh... The idea is to show that chemists can also be "not so serious", that the science is fun and to transmit our enthusiasm to the students - probably the most important mission here.

\subsection{End of the Semester, Question and Answers and Getting ready for the Exam}

Dedicating two hours to enthusiasm and experiment out of 84 hours is of course not an excess, especially when the end of the semester nears. First semester students are typically very worried about how the exams will be. This is why at the end of my General Chemistry lecture, I give them a test exam. The regular examination is a written one over two hours, with 20 multiple choice questions, each for 1 point, and 10 open answer questions, each for 2 points. The text exam in the last week of the semester is half as long in terms of questions, and I only give 45 minutes for them to give the answers. This test exam is held almost like a true exam, in silence and excluding exchanges between the students. It is not counted into any grade, but rather intended to give them the opportunity to see where they stand with their knowledge. Most students take this opportunity seriously, but there are always some who do other homework during this hour, or they book their winter holidays online. During the second hour, the questions are solved together, and I ask them openly about who answered A, B, C, D or E, before I give them the answer. This is to see where weaknesses are, and it gives them (as well as myself) the necessary feedback.

Finally, the very last two-hour slot before the Christmas break is dedicated to any questions that they may have. Typically, $c a$. 100 students come for this session. The idea is that I take any question that they may have and will answer on the blackboard. In some years, this session was over after 15 minutes, sometimes it lasted one full hour, and once or twice, they profited over the entire two-hour slot, without even taking a break. With this, I usually close, but would answer still questions by email. The Moodle platform stays open all the time until the exam. Typically, in January, I would still get some questions, either via email or via Moodle.

\subsection{The Exam}

As the lecture is officially bilingual in French and German, the exam must also comply with that. As a result, a roughly 20-page long exam is produced for the two-hour written exam. Half of the points can be earned by answering correctly the 20 multiple choice questions, the other half by giving correct answers to open questions. Both question types cover the entire course content. The open questions may require calculations, drawing of molecules, explanations or definitions, and/or reasoning and logic. For roughly 300 students taking the exam in February, I usually receive two trolleys with four paper boxes full of exams that are delivered to my office. These keep me busy over roughly a week for corrections. Often, but not always, I ask my research group to help with the multiple-choice questions' corrections, whereas I insist on correcting the open questions myself.

Students typically answer in German or French, some in English, and some know that the professor also understands Italian, so that they write their answers in Italian. This is not so difficult to understand with knowledge in Latin, Spanish and Italian on top of a very good basis of French.

Typically, the students cope better with the multiple-choice questions than the open questions. Among the latter, text questions which require logic reasoning and calculations seem to be more difficult than, for instance, drawing the three-dimensional structures of given molecules. Thus, calculating dilutions, copying given data from the text question into a formula, or simply transforming mmol into mol can represent unsurmountable problems. But also three-dimensional, perspective drawing is a challenge, in particular for questions around chirality. This is when it pays back if students have copied themselves the organic chemistry part instead of taking photos of the blackboard (or the openboard screen).

The exam is set up such that they succeed with $50 \%$ of the points (overall 40 points possible), and the typical success rate used to be around $66 \%$ until 2018. The statistical distribution of grades featured so far a double Gauss-shaped curve with a small maximum around 3.0-3.5 for the failed exams, and a larger maximum around 4.5-5.0 for the successful ones.

Without changing my way of teaching, nor drastic changes in the style of questions, the success rate has slowly decreased since 2018 and has reached $c a$. 50\% in February 2020. There is now only one maximum in the grade distribution that is around 4.0 or even slightly below. In particular, the results in the open questions have worsened, and a lot of strange mistakes are being made by students. For example, many do not consider the ' $\mathrm{m}$ ' in front of 'mol' or ' $\mathrm{k}$ ' in front of ' $\mathrm{J}$ ', and therefore miss by a factor of one thousand, others get the factor wrong and define a millimol as $0.01 \mathrm{~mol}$. In text questions, in which I give them data such as the temperature in Kelvin, they use suddenly a completely different value or they change to ${ }^{\circ} \mathrm{C}$, which of course gives wrong results. Whether or not these types of mistakes are the result of decreasing concentration spans among the 'i-phone generation' is currently under investigation (see Section 4).

\section{Teaching under Special Conditions: COVID-19}

Since mid-September 2020, the new semester started with 322 registered students for the General Chemistry course, and this in a time where the lecture hall has half of its seats blocked for Corona-reasons. Since the University of Fribourg decided to go for presence teaching as much as possible, in particular for the first semester students, the big lecture hall was equipped with a camera for live streaming.

General Chemistry is, together with the basic mathematics courses, first semester physics and biology, among four big lecture series called the propedeutics, for which the audience is essentially the same. Thus, all four teachers decided to go with the same rotation principle, having all students except the biomedical students present in the lecture hall during weeks $1,3,5$, etc. of the semester, while the biomedical students show up in weeks 2, 4,6 , etc., and the non-present students would be able to watch the lecture from home or outside the lecture hall. Furthermore, the seats were numbered and at the beginning of each lecture, students needed to register with their seat number.

Live streaming (we use the program MS-TEAMS for this, but ZOOM probably works just as well) is however a challenge in a lecture hall with $c a .150$ students present, and roughly the same number of students on the screen, all while teaching and showing experiments. This cannot be done alone. Thus, since the beginning of the semester, two of my PhD students help me setting up the live stream to make sure that everything works well. We set 
up a TEAMS group with the three of us as owners of the group, and the students being members. This was to make sure that the course can be recorded and can always be found in the lecture group. It was however a bit of a mess at the beginning as students tried to record themselves and/or played with mute buttons. Thus, one of my $\mathrm{PhD}$ students always had to stay on during the lecture to e.g. make sure that the recording worked well (for those who could only watch the lecture in a delayed way or wanted to repeat it), and to tell me if there is a serious problem in the chat or with the microphone. So, we needed to prepare all roughly 15 minutes in advance to set up experiments and live call, and during the short break between the two hours and more particular after the lecture, the live and chat questions were answered. Students sometimes also asked questions during the lecture, which I needed, of course, to repeat before answering, in order to make sure all heard the question(s) (Fig. 1).

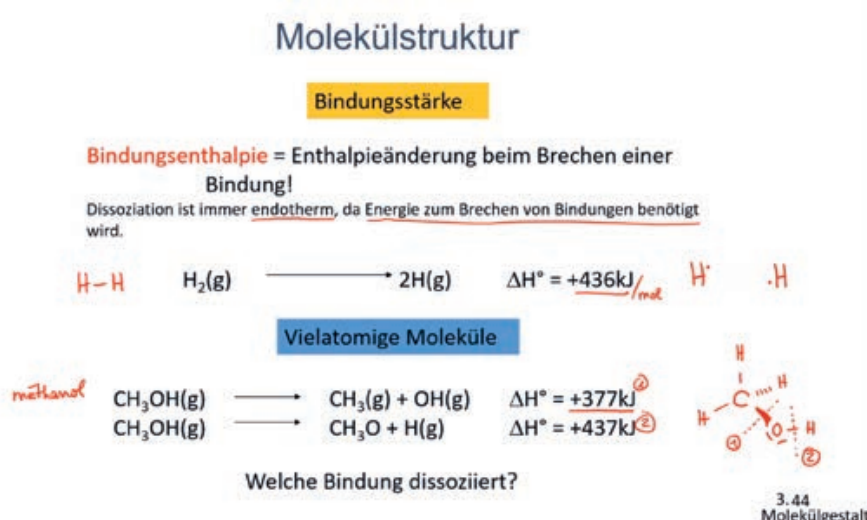

Fig. 1. Teaching live and on TEAMS, in German and French, explaining and annotating.

Special skills are needed when live experiments are performed as this requires quitting the annotated PowerPoint presentation, re-orienting the camera, zooming correctly and making sure that students see the projection live on the screen as well as in zoom. This requires significant training, and in many cases, an additional hand-held camera is needed for close-ups. But special times need special measures, and this COVID-period clearly requires additional (wo-)manpower to cope with teaching (not only in the classroom, but also for the teaching laboratories, by the way). Since we do not have more personnel than usual, this clearly means working overtime if research is not to be neglected.

All exercises were now moved directly into Moodle exercises that are automatically corrected. The professors and assistants can clearly see which exercises are well handled and where problems remain. The exercise sessions are thus more focused on the weak spots of students. Furthermore, we chose to introduce the option for students to submit a 'Hot question' in an anonymous way, if they prefer this. Other students can then give thumbs up and give thus weight to a submitted question, showing its relevance. Thus, as additional service, I usually reply to the hot questions on the weekend in one message to all students. There are typically 3-5 questions, 1-2 of which that are particularly 'liked'. This seems to be well appreciated, just as much as replying to chat questions at the end of each lecture.

So far, the experience with half presence, half online teaching is an exciting one and it is quite positive. Indeed, a new interaction among the online students can be observed: some chat questions are answered by other students who know the answer. This is not the case in live teaching. This is also because I usually cannot immediately reply to the chat questions, as this has to wait until the break or after the lecture. Another more fun aspect is that students ask their questions sometimes by using gifs, e.g. mini-excerpts from a movie or a TV or Netflix series. It gives a certain intimacy within the TEAMS group.

\section{Conclusions, Measures and Perspectives}

In normal times, teaching a large multilingual class with very different basic knowledge is a special challenge and requires at least bilingual, in particular German- and French-speaking teachers at our University. Mixing different teaching techniques, such as PowerPoint, blackboard and uniboard as well as live experiments to illustrate the theory makes the General Chemistry enjoyable and edutaining. In COVID-times, this challenge is yet increased, but offers new possibilities and perspectives. A true team(s) spirit develops, and students start talking to each other via chats as questions live and via chats seem more intense. Mask-wearing discipline is excellent, so is the online registration procedure.

After the observations over the past two years that exam average grades are decreasing, specific action was taken. To start with, a meeting with all colleagues teaching propedeutic courses in physics, maths and biology was called, and we observed similar trends in all fields. This motivated us to share the problems and try to train students better in basic mathematics (in addition to the level requested anyhow), to train them in text exercises and to better interconnect the different areas, solving problems in common.

Furthermore, in collaboration with the Swiss Center for Middle Schools and the Canton of Fribourg, we started to establish common platforms for high school and university teachers. Thus, in 2019, three such platforms were launched in mathematics, chemistry and law/economy, while this year, the platforms for physics, French, German and Ancient Languages will kick-off their activities. This increases the contacts between the Fribourg schools and the University of Fribourg. It helps to intensify professional training for high school teachers by the university teachers, and, in the case of the Chemistry platform for example, to bring schoolchildren to University labs for certain experiments in order to illustrate schooling chapters. This should enable teachers to keep the graduation level high enough to guarantee a smooth transition for schoolchildren to the university.

The future will show if we will go back to teaching methods of the pre-COVID times, or if we continue to offer hybrid new teaching methods, which will be fine-tuned. Meanwhile, the interaction between high school teachers and University professors (in particular the ones teaching freshmen) is important in identifying gaps in study programs, which need to be dealt with in order to maintain a transition from the high schools to the universities as smooth as possible.

\section{Acknowledgements}

The author thanks Cyrill Mouthon from the Dean's Office for providing the statistics for the General Chemistry lectures over the past years. Bernd Giese and Christian Bochet thankfully read through the text with a critical eye.

Received: November 1, 2020

[1] K.-H. Günther, 'Profiles of educators: Wilhelm von Humboldt (1767-1835)', Prospects 1988, 18, 127.

\section{License and Terms}

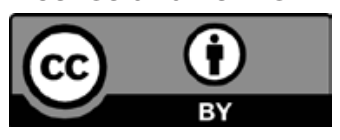

This is an Open Access article under the terms of the Creative Commons Attribution License CC BY 4.0. The material may not be used for commercial purposes.

The license is subject to the CHIMIA terms and conditions: (http:// chimia.ch/component/sppagebuilder/?view=page \&id=12).

The definitive version of this article is the electronic one that can be found at https://doi.org/10.2533/chimia.2021.39 